\title{
Hereditary chorea without dementia
}

\author{
PETER O. BEHANAND I A N B NE \\ From the Glasgow University Department of Neurology, Institute of Neurological Sciences, \\ Southern General Hospital, Glasgow
}

SUMMARY We describe here a distinct syndrome of chorea without dementia, occurring in three generations of a family and inherited as a mendelian dominant.

The causes of chorea occurring in childhood or in early adult life include inherited, metabolic, endocrine, infectious, or psychological diseases. The classical inherited disease of which chorea is the main symptom is Huntington's chorea, the inheritance following a mendelian dominant pattern. When this disorder presents in adults, chorea is almost always a prominent feature, but it is found only rarely when the disease begins in childhood (Wilson, 1968). Huntington's chorea is progressive and associated with intellectual deterioration. Other inherited conditions of which chorea may be a feature include Tay-Sach's disease (Markham and Knox, 1965), hepatolenticular degeneration (Wilson, 1912), the Lesch-Nyhan syndrome (Lesch and Nyhan, 1964), and the Hallervorden-Spatz syndrome (Hallervorden and Spatz, 1922).

Chorea may be a manifestation of rheumatic fever (Aron et al., 1965). It has also been described in a variety of diseases including polycythaemia rubra vera (Gautier-Smith and Prankerd, 1967), thyrotoxicosis (Fidler et al., 1971), subacute thyroiditis (Cohn et al., 1971), and idiopathic hypoparathyroidism (Simpson, 1952; McKinney, 1962). It can occur in patients taking phenothiazines (Singer and Wong, 1970), oral contraceptives (Riddoch et al., 1971), or alcohol (Mullin et al., 1970). Chorea has also been found in liver disease (Victor et al., 1965; Toghill et al., 1967), after infections including diphtheria (Critchley, 1924), or as a manifestation of syphilis (Münzer, 1935). It has been described as a complication of kernicterus (Fitzgerald et al., 1939), and of vascular diseases of the basal ganglia (Mitchell, 1874). Chorea has also been found in atrophy of the globus pallidus (Hunt, 1917), and as a habit spasm

Address for reprint requests: Dr P. O. Behan, Department of Neurology, Institute of Neurological Sciences, Southern General Hospital, Glasgow G51 4TF, Scotland.

Accepted 14 January 1977 or tic secondary to some psychological abnormality (Markham and Knox, 1965).

There are very rare reports in the literature of familial chorea occurring without dementia (Velander, 1931; Haerer et al., 1967; Pincus and Chutorian, 1967; Nutting et al., 1969; Sadjadpour and Amato, 1973). In these cases the onset was usually in early childhood and the course benign without intellectual impairment. In one instance, the chorea improved as the patient became older (Sadjadpour and Amato, 1973).

We report here a family in which chorea has occurred in three generations. The disease has had a benign course in the first two generations and in one member of the third generation, but in the propositus the chorea is severe and progressive. In all generations, however, there is no associated intellectual impairment.

\section{Case report}

TW (Unit No. 602070) was a 20 year old, right handed, male salesman. At the age of 3 years involuntary movements involving his face and limbs were noted by his parents. These movements were not progressive until the age of 12 years when he began making loud, involuntary, grunting noises. At the age of 18 years he sustained a minor head injury after a road traffic accident, and from this date became aware of a gradual increase in the severity of his movements, particularly those of his face, to such a degree that he was too embarrassed to go out in public other than to carry on his work. His gait, however, remained unaffected.

The patient's development was normal. He walked at 14 months and was described as of above average intelligence throughout his schooling, obtaining $O$ level passes before leaving at the age of 16 years to take up employment as a salesman. At school and at work he was frequently 
teased because of his movements, but his work record was good. He had no serious illnesses or operations. In July 1974 he was admitted to the Institute of Neurological Sciences for evaluation.

Examination at that time revealed an alert young man of slim build, with purposeless, continual movements of his face, hands, and arms. He grimaced, continually protruded his tongue, and showed coarse, irregular, side-to-side jerking of his head. Apart from these classical choreiform movements the rest of the neurological examination including neuro-ophthalmological examination, was entirely normal.

INVESTIGATIONS

Full blood count was normal, and the ESR was $7 \mathrm{~mm}$ per hour. Urine analysis, blood urea and electrolytes, serum calcium, phosphate, alkaline phosphatase, copper oxidase, magnesium and lipoprotein levels were normal. Wassermann reaction and VDRL tests were negative. Urine amino-acid chromatography revealed a normal pattern. Thyroid function studies were within normal limits. Radiographs of the chest and skull, together with an electroencephalogram repeated on several occasions, were normal. Lumbar pneumoencephalography suggested a mild degree of dilatation of the lateral ventricles only; cerebrospinal fluid examined at this procedure showed a total protein of $0.5 \mathrm{~g} / \mathrm{l}$, with a gamma globulin of 0.03 $\mathrm{g} / \mathrm{l}$. Slit lamp examination of the eyes was normal. A formal psychological assessment was undertaken which showed no abnormalities, the IQ on the Wechsler Intelligence Scale being reported as 100. This test was repeated one year later and showed no change.

CLINICAL COURSE

The patient had been on no drug therapy before admission. He was initially treated with tetrabenazine $25 \mathrm{mg}$ three times daily which was increased to $25 \mathrm{mg}$ four times daily. This failed to induce any remission in his symptoms. The treatment was changed to thiopropazate $5 \mathrm{mg}$ four times daily. After four months this treatment was stopped because his symptoms had not improved. Since then he has been treated for two months with deanol which resulted in no improvement, and has also had clonazepam $1 \mathrm{mg}$ twice daily for three months with no effect. He feels that within the last year there has been a slow progression in his illness.

FAMILY HISTORY

TW is one of three siblings (Figure). His 14 year old sister is asymptomatic but his brother, aged
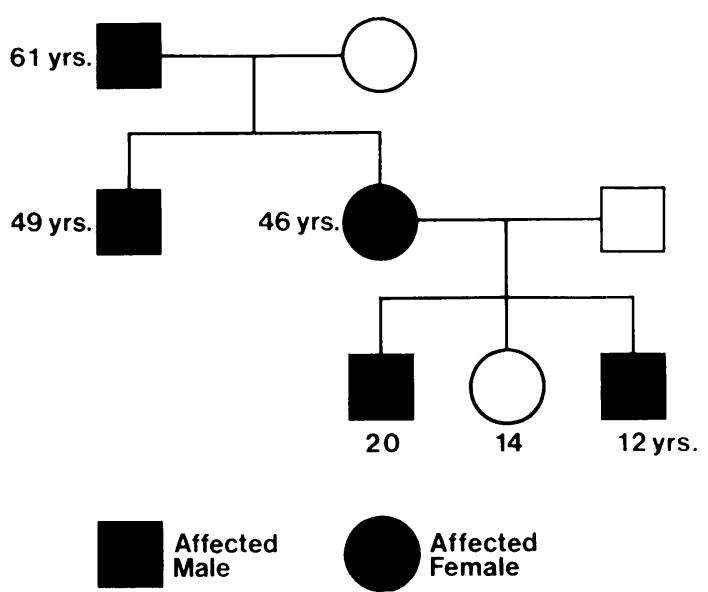

Figure Pedigree chart of inherited chorea without dementia

12 years, has had involuntary movements of the face and upper limbs for approximately one year. The patient's mother (aged 46 years) has had involuntary movements of the face since childhood: these have, if anything, become less marked over the years. The brother and the mother were ex amined by us and choreiform movements werea noted. These were of the same type as the propo situs but much less marked. It was also noted 8 that both had good personalities and appeared to be of normal intelligence as judged by conversa tion at several interviews. The patient's uncle, last seen by the family two years ago when aged 47 years, has had involuntary movements of the face and limbs for most of his life, with the severity of the movements becoming progressively less with age. His whereabouts at present are unknown and, therefore, he was not examined. The patient's grandfather apparently had involuntary movements of his face and limbs but his daughter's recollection of these was that they became more obvious until shortly before his death at the age of 61 years. He had no intellectual deterioration and remained at his work as a London policeman until his death. Clearly, the choreiform movements, while noticeable to his family, were not sufficient to prevent him from carrying out his duties.

\section{Discussion}

We have documented here a family in which chorea without dementia occurred in three generations. The commonest cause of inherited chorea is Huntington's disease, and in a recent survey it has been suggested that about $1 \%$ of all cases of 
this disorder may occur in early childhood (Jervis, 1963). The syndrome described here is clearly distinguishable from Huntington's chorea for a variety of reasons.

Huntington's chorea is very rare in the first 10 years of life. The mean age of onset of the disease has been calculated to be 44 years of age with a standard deviation of about 11 years. Jervis (1963) in a study of the literature on 2394 cases found seven occurring before the age of 5 years and 13 between the ages of 6 and 10 years. The clinical manifestation of the disorder in childhood, however, differs from that in the adult. The characteristic choreiform movements are usually absent and instead there is muscular twitching, of ten confined to the face. Myoclonic movements, quite different from chorea and limited to a few muscle groups, are occasionally found but rigidity rather than chorea is the main motor manifestation in these children, as it is very occasionally in adults with Huntington's disease (Bittenbender and Quadfasel, 1962). The rigidity in the childhood form may be explained by the different pathological findings since the putamen is involved to a greater extent than it is in the adults. It has been shown in the adult with Huntington's disease who has rigidity as the principal manifestation, however, that destruction of the putamen is especially severe (Campbell et al., 1961).

In some cases cerebellar signs predominate in the first stage of the disease in children, with rigidity appearing towards the end. Cerebellar findings were reported in four of seven children by Markham and Knox (1965), in two of the patients of Jervis (1963) (and in an adult with Huntington's disease (Birnbaum, 1941)). The pathological basis for these cerebellar signs is thought to be a loss of Purkinje's cells, with gliosis, in the molecular layer of the cerebellum, and reduction of neurones in the dentate nuclei and the granular layer. A decrease in cells in the inferior olive has also been reported (Jervis, 1963).

In his review of reported cases of Huntington's chorea in childhood, Jervis (1963) found hyperkinesis and rigidity with mental deterioration and epilepsy, following a steadily progressive course, to be the commonest clinical picture. Mental deterioration is a consistent feature of all cases reported in the literature. Indeed, according to Jervis (1963), impairment of mentality is more conspicuous and more rapidly progressive in the child than it is in the adult with the disease. This was the finding also of Markham and Knox (1965). Convulsions are rare in the adult but common in the child, occurring in $50 \%$ of cases (Notkin, 1931; Meckler and Hinshaw, 1973). The electro- encephalograms in childhood cases studied by Jervis (1963) were abnormal as are the electroencephalographic results in adult Huntington's chorea (Foster and Bagchi, 1949). The rate of progression of all symptoms is greater in the childhood form than it is in the adult (Markham and Knox, 1965; Myrianthopoulos, 1969).

Our patient's illness clearly differs from the childhood variety of Huntington's chorea. Nor is it similar to the other forms of chorea which may occur in childhood-for example, Sydenham's or rheumatic chorea. This latter disease is found in association with streptococcal infections and is non-familial and self-limiting (Lessof and Bywaters, 1956). Some degree of weakness is nearly always found, which may be quite conspicuous. Other signs of rheumatic infection may be present, such as a high ASO titre, rheumatic arthritis, erythema nodosum, or cutaneous nodules. A cardiac murmur is detected in one-third of cases (Aron et al., 1965). There may be other symptoms and signs such as aphasia, seizures, memory disturbances, psychotic states, or hemiplegia. Sydenham's chorea usually has a course varying from three to six months with a maximum of about two years. It is a sporadic condition and there is little difficulty in distinguishing it from our case. There is no similarity either to chorea gravidarum which may be found in association with collagen disorders (Donaldson and Espiner, 1971). The clinical findings and laboratory values in our case eliminate the diagnoses of polycythaemia rubra vera, thyrotoxicosis, subacute thyroiditis, Wilson's disease, idiopathic hypoparathyroidism, and drug reactions.

Mount and Reback (1940) and Williams and Stevens (1963) have described familial paroxysmal choreoathetosis. This condition differs from ours in that it shows a recessive inheritance, and the clinical picture is dissimilar with involuntary 'bizarre' writhing movements of the arms, legs, and trunk, and grotesque posturing and grimacing, oscurring only in bouts, the patient being normal in between. The electroencephalogram is usually abnormal. Attacks are often precipitated by alcohol, coffee, tea, fatigue, exercise, and hunger. Some patients show a good response to anticonvulsants (Pryles et al., 1952).

Other authors have described an inherited chorea with no evidence of intellectual loss: we have been able to find five reports of families which bear some resemblance to our own. Velander (1931) described three families in which chorea involved predominantly the tongue. It developed in early childhood, was non-progressive and associated with cerebellar signs. There was 
also mild variation within the three families which is different from our family where the affected patient has severe and incapacitating chorea, while his brother, mother, uncle, and grandfather have only a mild illness. Like Velander's case, however, our patient does have maximum involvement of the tongue.

In the cases described by Nutting et al. (1969), the choreoathetoid movements were limited to the extremities and neck and did not involve the face. An autosomal recessive inheritance was involved. This condition is, therefore, also different from that in our case. Sadjadpour and Amato (1973) describe six affected individuals in three generations with a choreiform condition occurring early in childhood and principally affecting gait. The authors noted that: 'the affected individuals did not walk until they were 3-6 years old'. There was quite marked variation among the affected members. Interestingly enough the condition was reported by the family to improve as the individuals became older so that the younger children were more seriously handicapped. These findings alone make the disease different from the one we describe. Slight facial grimacing was seen in the two more seriously affected children. Laboratory findings were normal, apart from an alkaline phosphatase in the upper range of normal in all the affected children. The chorea was traced through five generations, and was inherited as a simple mendelian dominant. This family bears certain resemblances to that described by Haerer et al. (1967) in which the condition began early in life and also affected gait so that falling and stumbling occurred. Pincus and Chutorian (1967) described three children who developed chorea between the ages of 2 and 10 years, with, in addition, cerebellar findings and intention tremor of the upper extremities. This condition was not progressive.

In all five reports (Velander, 1931; Haerer et al., 1967; Pincus and Chutorian, 1967; Nutting et al., 1969; Sadjadpour and Amato, 1973) the disease occurred in early childhood and was not progressive. As stated cerebellar signs were noted in two families, those of Pincus and Chutorian (1967) and Velander (1931).

The distinctive features of our patient appear to be the progressive nature of the chorea and the wide variation between his clinical findings and those of the affected members of his family. Our family is similar to the others described in that there is no intellectual loss and the chorea is benign apart from in the propositus. No biochemical abnormalities were detected. Inheritance is mendelian dominant. There is no improvement with drugs.
The syndrome described here does bear some resemblance to Huntington's chorea in that the chorea is gross and inheritance is mendelian dominant in type. There is no intellectual loss in our family, which militates against this diagnosis, but, there are very rare reports in the literature of families with Huntington's chorea in which certain members had the chorea but not the dementia (Loewenfeld, 1899). It must be stressed that this is a very rare occurrence. Nonetheless, it may be that our family represents a forme fruste of Huntington's disease and together with the other families showing a hereditary benign chorea, serves to indicate that there may be a wider clinical variation in Huntington's chorea than has generally been thought to be the case.

\section{References}

Aron, A. M., Freeman, J. M., and Carter, S. (1965). The natural history of Sydenham's chorea: review of the literature and long-term evaluation with emphasis on cardiac sequelae. American Journal of Medicine, 38, 83-95.

Birnbaum, G. (1941). Cronisch-progressive chorea mit kleinhirnatrophie. Archiv für Psychiatrie und Nervenkrankheiten, 114, 160-182.

Bittenbender, J. B., and Quadfasel, F. A. (1962). Rigid and akinetic forms of Huntington's chorea. Archives of Neurology (Chicago), 7, 275-288.

Campbell, A. M. G., Corner, B., Norman, R. M., and Urich, H. (1961). The rigid form of Huntington's disease. Journal of Neurology, Neurosurgery, and Psychiatry, 24, 71-77.

Cohn, D. F., Herishanu, Y., and Streiffer, M. (1971). Subacute thyroiditis complicated by chorea minor. Bulletin of the Los Angeles Neurological Society, 36, 58-60.

Critchley, M. (1924). Post-diphtheritic 'chorea'. British Journal of Children's Diseases, 21, 188-192.

Donaldson, I. M., and Espiner, E. A. (1971). Disseminated lupus erythematosus presenting as chorea gravidarum. Archives of Neurology (Chicago), 25, 240-244.

Fidler, S. M., O'Rourke, R. A., and Buchsbaum, H. W. (1971). Choreoathetosis as a manifestation of thyrotoxicosis. Neurology (Minneapolis), 21, $55-57$.

Fitzgerald, G. M., Greenfield, J. G., and Kounine, B. (1939). Neurological sequelae of 'kernicterus'. Brain, 62, 292-310.

Foster, D. B., and Bagchi, B. K. (1949). Electroencephalographic observations in Huntington's chorea. Electroencephalography and Clinical Neurophysiology, 1, 247-248.

Gautier-Smith, P. C., and Prankerd, T. A. J. (1967). Polycythaemia rubra vera and chorea. Acta Neurologica Scandinavica, 43, 357-364.

Haerer, A. F., Currier, R. D., and Jackson, J. F. (1967). Hereditary non-progressive chorea of early 
onset. New England Journal of Medicine. 276, 1220-1224.

Hallervorden, J., and Spatz, H. (1922). Eigenartige Erkrankung im extrapyramidalen system mit besonderer Beiteiligung des Globus Pallidus und der Substantia nigra. Zentralblatt für die gesamte Neurologie, 79, 254-302.

Hunt, J. R. (1917). Progressive atrophy of the globus pallidus. (Primary atrophy of the pallidal system.) Brain, 40, 58-76.

Jervis, G. A. (1963). Huntington's chorea in childhood. Archives of Neurology (Chicago), 9, 244-257.

Lesch, M., and Nyhan, W. L. (1964). Familial disorder of uric acid metabolism and central nervous system dysfunction. American Journal of Medicine, 36, 561-570.

Lessof, M. H., and Bywaters, E. G. (1956). The duration of chorea. British Medical Journal, 1, 15201523.

Loewenfeld, L. (1899). Sur Lehre von der hereditaren (Huntington's chorea). Zentralblatt für Nervenheilkunde, 22, 321-327.

McKinney, A. S. (1962). Idiopathic hypoparathyroidism presenting as chorea. Neurology (Minneapolis), 12, 485-491.

Markham, C. H., and Knox, J. W. (1965). Observations on Huntington's chorea in childhood. Journal of Pediatrics, 67, 46-57.

Meckler, R. J., and Hinshaw, M. W. (1973). Isolated childhood chorea. In Advances in Neurology, Vol. 1, pp. 95-103. Edited by A. Barbeau, T. N. Chase, and G. W. Paulson. Raven Press: New York.

Mitchell, S. W. (1874). Post-paralytic chorea. American Journal of the Medical Sciences, 68, 342352.

Mount, L. A., and Reback, S. (1940). Familial paroxysmal choreoathetosis. Archives of Neurology and Psychiatry (Chicago), 44, 841-847.

Mullin, P. J., Kershaw, P. W., and Bolt, J. M. W. (1970). Choreoathetotic movement disorder in alcoholism. British Medical Journal, 4. 278--281.

Münzer, F. T. (1935). Choreatisches Syndrom der rechten oberen extremität als ausdruck einer Monosymptomatischen Lues Cerebri. Zeitschrift für die gesamte Neurologie und Psychiatrie, 152, 12-18.

Myrianthopoulos, N. C. (1969). Huntington's chorea. An appraisal of the genetic problem. In Progress in Neuro-genetics, pp. 509-516. Edited by A. Barbeau and J. R. Brunette. Excerpta Medica Foundation: Amsterdam.

Notkin, J. (1931). Convulsive manifestations in Huntington's chorea. Journal of Nervous and Mental Diseases, 74, 149-160.

Nutting, P. A., Cole, B. R., and Schinke, R. N. (1969). Benign, recessive inherited choreoathetosis of early onset. Journal of Medical Genetics, 6, 408-410.

Pincus, J. H., and Chutorian, A. (1967). Familial benign chorea with intention tremor: a clinical entity. Journal of Pediatrics, 70, 724-729.

Pryles, C. V., Livingston, S., and Ford, F. R. (1952). Familial paroxysmal choreoathetosis of Mount and Reback. Pediatrics, 9, 44-47.

Riddoch, D., Jefferson, M., and Bickerstaff, E. R. (1971). Chorea and oral contraceptives. British Medical Journal, 4, 217-218.

Sadjadpour, K., and Amato, R. S. (1973). Hereditary non-progressive chorea of early onset-a new entity? In Advances in Neurology, Vol. 1, pp. 7991. Edited by A. Barbeau, T. N. Chase, and G. W. Paulson. Raven Press: New York.

Simpson, J. A. (1952). The neurological manifestations of idiopathic hypoparathyroidism. Brain, 75, 76-90.

Singer, K., and Wong, M. (1970). Severe persistent chorea with phenothiazine therapy. Postgraduate Medical Journal, 46, 633-634.

Toghill, P. J., Johnston, A. W., and Smith, J. F. (1967). Choreoathetosis in porto-systemic encephalopathy. Journal of Neurology, Neurosurgery, and Psychiatry, 30, 358-363.

Victor, M., Adams, R. D., and Cole, M. (1965). The acquired (ncn-Wilsonian) type of chronic hepatocerebral degeneration. Medicine, 44, 345-396.

Velander, F. G. H. (1931). Arftkighetsstudier inom trenne slakter med hereditar tremor. Nordisk Medicinsk Tidskrift, 3, 102-108.

Williams, J., and Stevens, H. (1963). Familial paroxysmal choreo-athetosis. Pediatrics, 31, 656-659.

Wilson, J. (1968). Genetically determined neurological diseases in children. In Biochemical Aspects of Neurological Disorders, pp. 250-267. Edited by J. N. Cumings and M. Kremer. F. A. Davis Co.: Philadelphia.

Wilson, S. A. K. (1912). Progressive lenticular degeneration: a familial nervous disease associated with cirrhosis of the liver. Brain, 34, 295-509. 